\title{
Características ornamentais de plantas do Bioma Pampa ${ }^{(1)}$
}

\author{
ELISABETH TEMPEL STUMPF(2), CATIA MARIA ROMANO(3), ROSA LÍA BARBIERI(4), GUSTAVO HEIDEN(5), \\ SÍNTIA ZITZKE FISCHER ${ }^{(6)}$, LAUÍS BRISOLARA CORREA ${ }^{(7)}$
}

\begin{abstract}
RESUMO
O resultado da herança genética confere às plantas características específicas, que se revelam em elementos como forma, cor ou textura. Em alguns casos, esse conjunto de características expõe atributos estéticos que conferem qualidades ornamentais. $\mathrm{O}$ Bioma Pampa apresenta uma grande diversidade de espécies nativas, com características que sinalizam potencial para uso no paisagismo. A inserção dessas plantas em cultivos comerciais e sua posterior utilização são formas efetivas de colaborar com a conservação ex situ, divulgação e valorização da flora nativa. Com base nesse cenário, o presente trabalho teve por objetivo identificar espécies nativas do Bioma Pampa, na região Sul do Rio Grande do Sul, Brasil, que apresentem elementos estéticos apropriados para o paisagismo, além de organizar as informações sobre suas características ornamentais. Foram descritos a forma, o hábito de crescimento, a textura, o aroma e a cor das estruturas de maior valor ornamental, e indicadas as possibilidades de uso. As espécies descritas foram Campomanesia aurea, Colletia paradoxa, Daphnopsis racemosa, Eriocaulon magnificum, Maytenus muelleri, Schinus lentiscifolius, Scoparia ericacea, Senecio bonariensis e Solanum granulosoleprosum.

Palavras-chave: plantas nativas, características ornamentais, paisagismo.
\end{abstract}

\section{ABSTRACT}

\section{Ornamental characteristics of plants from Pampa Biome}

The result of the genetic inheritance confers specific characteristics to the plants that are revealed in elements such as form, color or texture. In some cases, this assembly of characteristics exposes esthetic attributes that confer ornamental quality to the plants. The Pampa Biome presents a large diversity of native species that possess characteristics with potential to be used in landscaping. The insertion of these plants in commercial cultivations and subsequent utilization are effective forms to collaborate for $e x$ situ conservation, disclosure and valorization of the native flora. Therefore, the present work had the objective of identify native species of the Pampa Biome, in the Southern region of Rio Grande do Sul State, Southernmost Brazil, that presents appropriate esthetic elements for landscaping use and organize the information about its ornamental characteristics. Morphology, habit and the texture, fragrance and color of the structures of higher ornamental value were described, with indication of the possibilities of use. The species described are Campomanesia aurea, Colletia paradoxa, Daphnopsis racemosa, Eriocaulon magnificum, Maytenus muelleri, Schinus lentiscifolius, Scoparia ericacea, Senecio bonariensis and Solanum granulosoleprosum.

Keywords: native plants, ornamental characteristics, landscaping.

\section{INTRODUÇÃO}

No Brasil, o Bioma Pampa está representado somente no Rio Grande do Sul, onde ocupa uma área de cerca de 17,64 milhões de hectares (COLLARES, 2006), o que, de acordo com o IBGE (2008), corresponde a 63\% da área total do Estado. Além dos campos propriamente ditos, o Pampa inclui outros ecossistemas, como banhados, e matas ciliares e de galeria (BORTOLUZZI \& SOUZA, 2007).

Todas as paisagens desse bioma possuem beleza e valor ecológico peculiares, e sua diversidade abriga uma flora própria e valiosa, porém ameaçada (BACKES, 2005). NABINGER (2007) estima que a vegetação do Pampa seja composta por cerca de 3.000 espécies vasculares. A paula- tina supressão da vegetação, no entanto, constitui um grave problema ambiental, que afeta diretamente a biodiversidade do local. VALLS (2006) alerta que, quanto maior a pressão sobre os ecossistemas naturais, fonte de diversidade biológica e genética, maior a necessidade de se conservar o que vem sendo negligenciado em função das mudanças sociais e econômicas.

Levando-se em conta o atual quadro de devastação do ambiente, fica evidente a necessidade de serem desenvolvidas pesquisas com foco na aplicação das espécies vegetais. Nessa perspectiva, portanto, a aplicação prática de plantas nativas com potencial ornamental, como para uso no paisagismo, pode contribuir para a valorização e conservação da biodiversidade.

\footnotetext{
${ }^{(1)}$ Recebido para publicação em 22/09/2008 e aceito em 12/05/2009.

(2) Bolsista Pós-doutor Júnior do CNPq, e-mail: elisabeth.stumpf@gmail.com

(3) Bolsista Recém-doutor Fundação de Amparo à Pesquisa do Estado do Rio Grande do Sul (FAPERGS).

(4) Pesquisador da Embrapa Clima Temperado.

(5) Mestrando, Bolsista CNPq-Protax. Escola Nacional de Botânica Tropical, Jardim Botânico do Rio de Janeiro.

(6) Doutoranda Universidade Federal de Pelotas

(7) Biólogo
} 
No Brasil, no entanto, desde a época colonial o paisagismo prioriza o uso de plantas exóticas sobre as nativas. Em contrapartida, diversas plantas da flora nacional, aqui pouco valorizadas, são bastante apreciadas e utilizadas em outros países (FISCHER et al., 2007). Plantas brasileiras certamente já foram inseridas no mercado nacional, mas, muitas vezes, apenas como resultado de pesquisas efetuadas no exterior. HEIDEN et al. (2007) reportam que muitas de nossas espécies nativas foram levadas, multiplicadas e hibridizadas em outros países e, ao serem importadas pelo Brasil como novidades, tiveram boa aceitação e foram incorporadas ao mercado. Isso certamente atesta o potencial de uso de nossas plantas e explicita o quão dependente o país ainda é do aval de outros mercados.

Os mesmos autores mencionam que a tendência que vem se fortalecendo no paisagismo moderno está relacionada à redução, ou mesmo à substituição das espécies ornamentais exóticas por nativas. HEIDEN et al. (2006), no entanto, alertam para o fato de que a demanda por esse tipo de planta para uso em projetos paisagísticos não está ainda adequadamente atendida pelo setor produtivo nacional. Por outro lado, é preciso estabelecer estratégias que possibilitem a inserção de uma nova planta no mercado, a começar pela definição de quais características podem ser consideradas ornamentais (O'BRIEN, 1996), tarefa que WEISS (2002) considera complexa, pois a percepção estética envolve sentimentos subjetivos e pessoais. Além disso, o uso de plantas na floricultura ou no paisagismo deve atender às necessidades de cada uma das áreas. TOMBOLATO (2008) ressalta que, de modo geral, toda planta pode ter uso ornamental, bastando que se harmonize com o ambiente a ser decorado e/ou que atenda ao objetivo de uso, seja em jardins internos ou externos, como decorações, presentes ou artesanato. Sendo assim, características como coloração, textura, porte, fenologia, aroma, adaptabilidade ao ambiente, ciclo ou atração da avifauna local, motivam a preferência por determinadas plantas.

No contexto apresentado, o presente trabalho foi desenvolvido com o objetivo de identificar espécies nativas do Bioma Pampa, na região sul do Rio Grande do Sul, Brasil, que apresentem elementos estéticos apropriados para uso no paisagismo, bem como disponibilizar as informações sobre suas características ornamentais.

\section{MATERIAL E MÉTODOS}

As plantas foram escolhidas a partir de observações a campo na área abrangida pelos municípios de Canguçu, Capão do Leão, Pelotas e Piratini, na região sul do Rio Grande do Sul.

Exsicatas das espécies definidas como potencialmente ornamentais foram preparadas, a fim de proceder e atestar a sua correta identificação botânica. Posteriormente, foram levadas ao Herbário da Embrapa Clima Temperado, e informações gerais sobre cada uma delas foram obtidas a partir de revisão bibliográfica.

A avaliação das espécies, com base nas características previamente estabelecidas, foi feita por seis profissionais ligados à prospecção de recursos genéticos de plantas nativas e ao paisagismo. Para balizar a descrição das características ornamentais selecionadas e eliminar ao máximo as preferências pessoais, foram estabelecidas características consideradas essenciais para as finalidades de uso propostas (tabela 1).

Para a indicação de uso, as plantas foram categorizadas como: plantas para jardins -indicadas para a formação de maciços, cercas-vivas, bordaduras, forrações, ou para uso isolado - plantas para vasos - indicadas para o cultivo em recipientes de diferentes volumes -, ou plantas multifuncionais - indicadas tanto para jardins como para o cultivo em vasos. 
Tabela 1. Descrição dos elementos utilizados para a avaliação das características ornamentais de plantas nativas do Bioma Pampa - ao sul do Rio Grande do Sul - com possibilidade de uso no paisagismo.

\begin{tabular}{ll}
\hline Característica & Descrição \\
\hline Hábito & Árvore - plantas lenhosas providas de caule único \\
& Arbustos - plantas lenhosas com caules múltiplos, ramificados desde a base \\
& Herbáceas - plantas de pequeno porte e com caule tenro \\
& Verticalizada - quando a altura é maior que o diâmetro da copa \\
$\begin{array}{l}\text { Forma (relacionada à copa de árvores } \\
\text { ou à conformação geral de arbustos) }\end{array}$ & Horizontalizada - quando o diâmetro da copa é maior que a altura \\
& Equilibrada - quando o diâmetro da copa é semelhante à altura \\
Simetria & Simétrico - quando a conformação geral é uniforme; \\
& imprime unidade e organização \\
& $\begin{array}{l}\text { Assimétrico - quando os ramos se desenvolvem em diferentes } \\
\text { direções; desuniforme }\end{array}$ \\
Textura da(s) estrutura(s) de maior valor & Brilhante ou opaca \\
ornamental (folhas, ramos, caule, flores, frutos) & Lisa ou rugosa \\
& Pilosa ou glabra \\
Cor da(s) estrutura(s) de maior valor ornamental & Determinada visualmente \\
(folhas, ramos, caule, flores, frutos) & \\
Aroma & Presente - agradável ou desagradável \\
& Ausente \\
\hline
\end{tabular}

Table 1. Description of the characteristics used to evaluate the ornamental characteristics of native plants from Pampa Biome, Southern Rio Grande do Sul state, Brasil, with possibility to landscaping use.

\begin{tabular}{|c|c|}
\hline Characteristics & Description \\
\hline Habit & $\begin{array}{l}\text { Tree - wood plants with single stem } \\
\text { Shrub - wood plants with multiple stems, branching near the base } \\
\text { Herb - small plants with tender stem }\end{array}$ \\
\hline $\begin{array}{l}\text { Shape (related to the trees crown or } \\
\text { to the shrubs structure) }\end{array}$ & $\begin{array}{l}\text { Vertical - height greater than the tree crown diameter } \\
\text { Horizontal - tree crown diameter greater than the height } \\
\text { Equable - crown diameter similar to height }\end{array}$ \\
\hline Symmetry & $\begin{array}{l}\text { Symmetric - uniform structure; get a feeling of unit and organization } \\
\text { Asymmetric - shoots growing in several directions; not uniform }\end{array}$ \\
\hline $\begin{array}{l}\text { Texture of the structure with great ornamental } \\
\text { value (leaves, shoots, stems, flowers, fruits) }\end{array}$ & $\begin{array}{l}\text { Shiny or opaque } \\
\text { Smooth or rough } \\
\text { Pilose or glabrous }\end{array}$ \\
\hline $\begin{array}{l}\text { Color of the structure with great ornamental } \\
\text { value (leaves, shoots, stems, flowers, fruits) }\end{array}$ & Visually inferred \\
\hline Scent & $\begin{array}{l}\text { Present - pleasant or disagreeable } \\
\text { Absent }\end{array}$ \\
\hline
\end{tabular}




\section{RESULTADOS E DISCUSSÃO}

As espécies nas quais se constataram características adequadas aos propósitos do trabalho foram Campomanesia aurea Berg., Colletia paradoxa (Spreng.) Escal., Daphnopsis racemosa Griseb., Eriocaulon magnificum
Ruhland, Maytenus muelleri Schwacke (= M. ilicifolia Mart. ex Reiss.), Schinus lentiscifolius Marchand, Scoparia ericacea Cham. \& Schltdl., Senecio bonariensis Hook. $\&$ Arn.e Solanum granulosoleprosum Dunal.

Os habitats onde foram localizadas estão listados na tabela 2.

Tabela 2. Habitat onde foram localizadas as populações das espécies nativas com características ornamentais para uso no paisagismo.

\begin{tabular}{ll}
\hline Espécie & Habitat \\
\hline Campomanesia aurea Berg. & remanescentes de campos \\
Colletia paradoxa (Spreng.) Escal. & campos pedregosos \\
Daphnopsis racemosa Griseb. & remanescentes de campos \\
Eriocaulon magnificum Ruhland & restinga \\
Maytenus muelleri Schwacke & campos pedregosos \\
Schinus lentiscifolius Marchand & campos pedregosos \\
Scoparia ericacea Cham. \& Schltdl. & campos arenosos \\
Senecio bonariensis Hook. \& Arn. & banhado \\
Solanum granulosoleprosum Dunal & margem de banhado \\
\hline
\end{tabular}

Table 2. Habitat where the native species with ornamental characteristics to use in landscaping were collected.

\begin{tabular}{ll}
\hline Species & Habitat \\
\hline Campomanesia aurea Berg. & grassland fragment \\
Colletia paradoxa (Spreng.) Escal. & stony field \\
Daphnopsis racemosa Griseb. & grassland fragment \\
Eriocaulon magnificum Ruhland & restinga \\
Maytenus muelleri Schwacke & stony field \\
Schinus lentiscifolius Marchand & stony field \\
Scoparia ericacea Cham. \& Schltdl. & Wetland \\
Senecio bonariensis Hook. \& Arn. & wetland border \\
Solanum granulosoleprosum Dunal &
\end{tabular}

Campomanesia aurea (figura 1), popularmente conhecida como araçá-rasteiro ou guabiroba-do-campo, é uma espécie da família Myrtaceae. É um arbusto perene, de pequeno porte, horizontalizado e assimétrico, e que, em determinados ambientes, pode alcançar até $1 \mathrm{~m}$ de altura. As folhas são persistentes, brilhantes, lisas, glabras e de coloração verde-escuro. Suas flores, que surgem no início do verão, são vistosas, brancas e de aroma agradável. Os fru- tos são bagas globosas comestíveis, que passam do verde ao amarelado no processo de amadurecimento. Por sua interessante arquitetura, delicadeza e seu pequeno porte, pela floração intensa e aromática, e pelos frutos, que atraem a avifauna, o araçá-rasteiro pode ser usado em jardins, como planta de destaque ou para compor maciços ou bordaduras, ou ainda para o cultivo em vasos, conferindo diferencial a ambientes externos. 

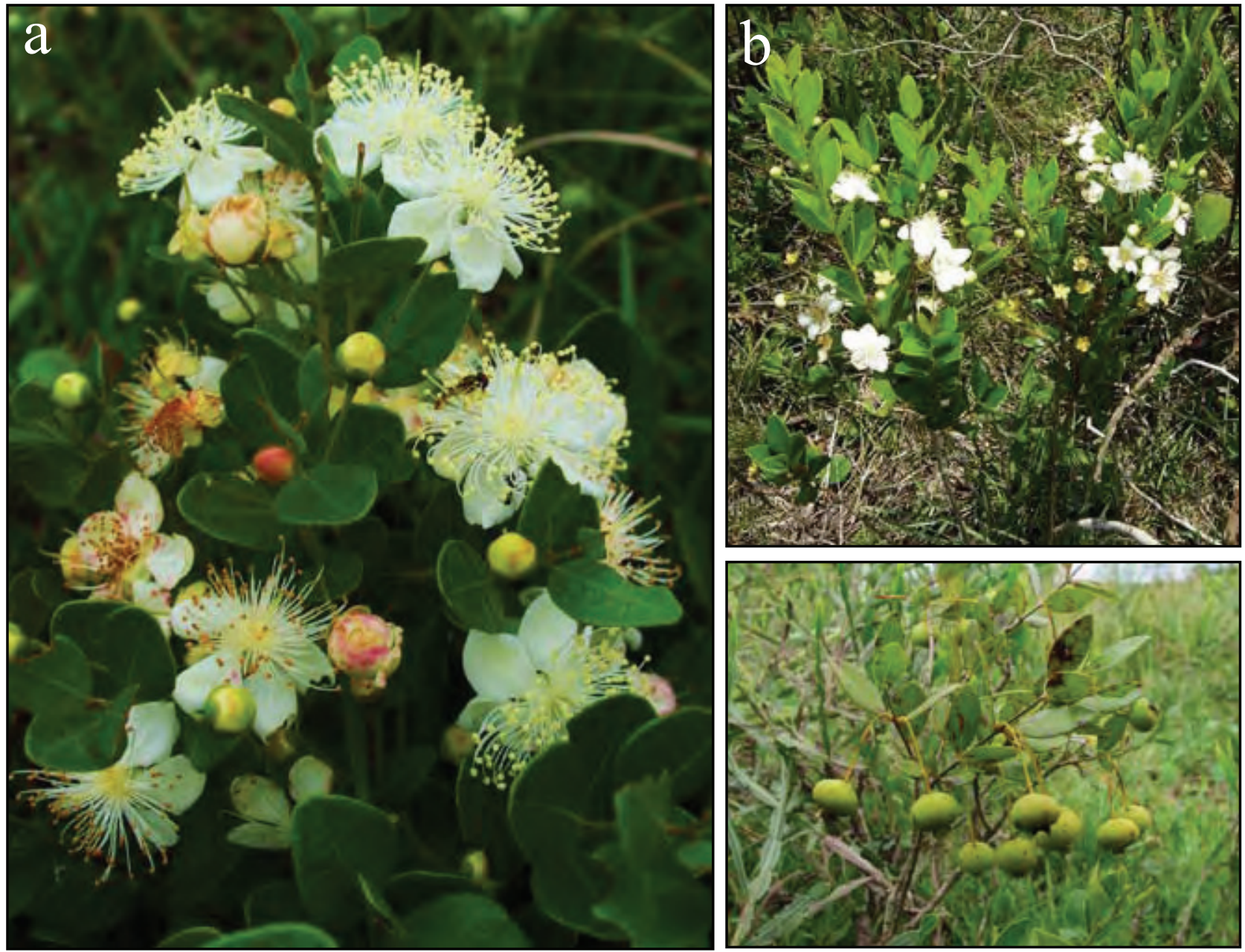

Figura 1. Campomanesia aurea: flores (a), hábito (b) e frutos (c).

Figure 1. Campomanesia aurea: flowers (a), habit (b) and fruits (c).

Colletia paradoxa (figura 2) pertencente à família Rhamnaceae é conhecida popularmente como quina-do-riogrande ou espinho-de-cruz. É um arbusto de crescimento lento, adaptado a ambientes áridos e com alta incidência de luz solar, com solos leves e bem drenados, o que indica uma baixa necessidade de irrigação. No Rio Grande do Sul, encontra-se na lista de plantas vulneráveis à extinção (BIODIVERSIDADE-RS, 2008). A espécie atinge de 1 a 2,5 $\mathrm{m}$ de altura e apresenta forma horizontalizada e assimétrica. Os ramos são opacos, lisos, glabros, verde-acinzentados e sem folhas, com forma de asas triangulares e grossos espinhos nas pontas. As flores, dispostas em fascículos, são brancas e exalam aroma agradável, suave e adocicado, que atrai insetos polinizadores. Por suas características ornamentais, pode ser usada isoladamente, como planta de destaque em uma composição, ou para a formação de cercas-vivas, principalmente com a finalidade de proteção ou isolamento, sempre a pleno sol. $\mathrm{O}$ aspecto inusitado e a coloração incomum dos ramos mostram adequação para o uso da espécie em jardins rochosos ou desérticos. Por outro lado, o crescimento lento favorece também o cultivo em vasos. A presença dos espinhos, no entanto, requer certo critério na escolha do lugar onde será colocada a planta, sendo mais indicado, um local de circulação restrita.

Daphnopsis racemosa (figura 3) é um arbusto encontrado tanto em locais ensolarados como sombreados. Pertence à família Thymelaeaceae, e é conhecido popularmente como embira. Atinge de 1 a $3 \mathrm{~m}$ de altura, e o diâmetro da copa tem medidas semelhantes, o que confere à planta uma forma equilibrada e simétrica. O tronco é liso, de coloração clara e com ramos glabros. Da casca, são extraídas fibras resistentes, usadas para artesanato. Suas folhas coriáceas são persistentes, brilhantes, lisas, glabras, com coloração entre verde-claro e verde-escuro, e dispostas alternada e espiraladamente ao redor do caule. As flores, com aroma agradável que atrai polinizadores, são pequenas, esbranquiçadas e nascem nas axilas das folhas no final do inverno. Enfim, a embira mostra ampla versatilidade para uso ornamental, podendo ser cultivada isoladamente ou formando bordaduras e cercas-vivas em jardins; também mostra condições para o cultivo em vasos, apresentando-se como substituta de espécies exóticas muito difundidas no País, como o buxinho (Buxus sempervirens L.), com a vantagem de dispensar podas de formação. 

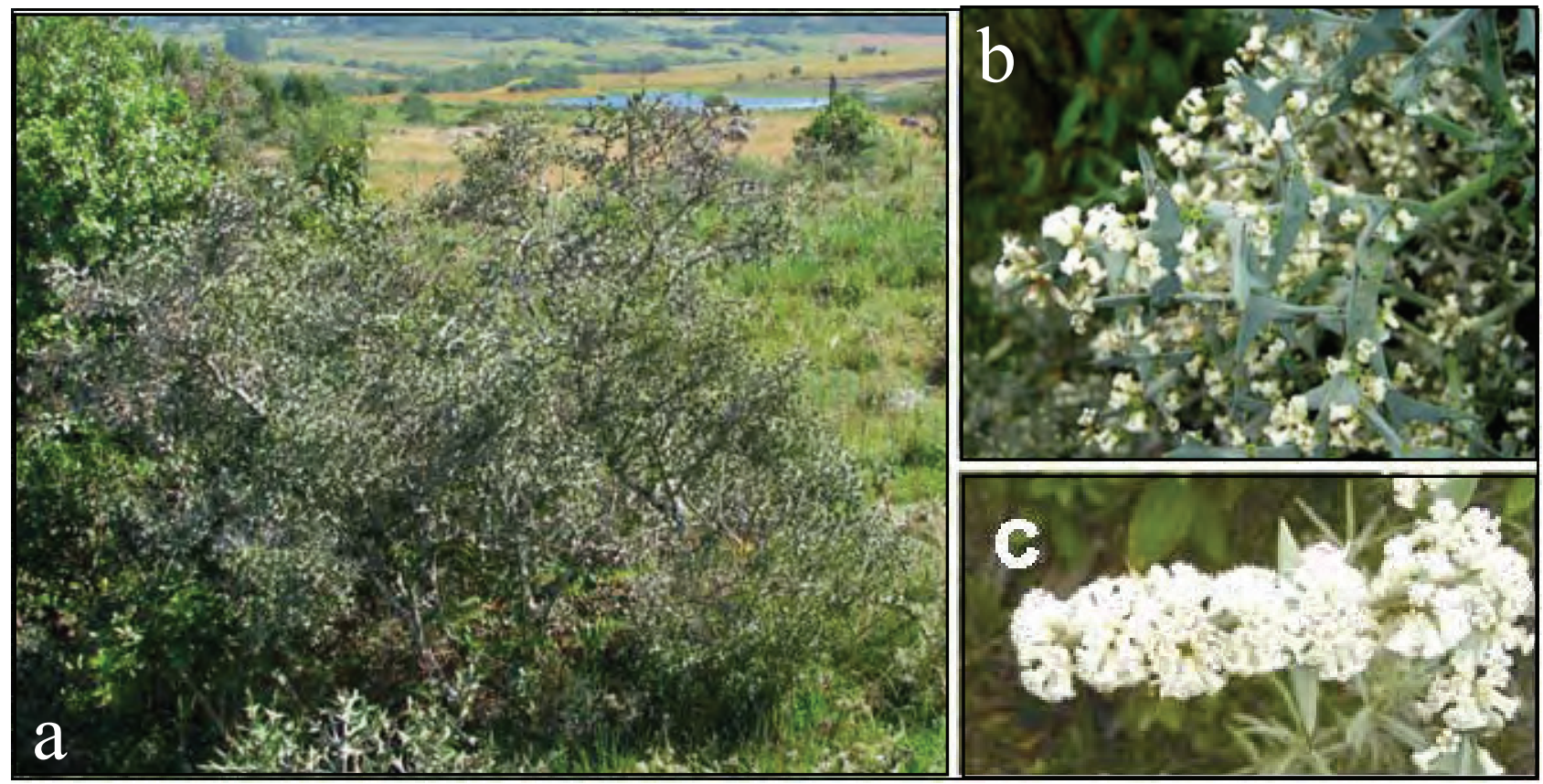

Figura 2. Colletia paradoxa: hábito (a) e ramos com flores (b, c).

Figure 2. Colletia paradoxa: habit (a) and stems with flowers (b, c).

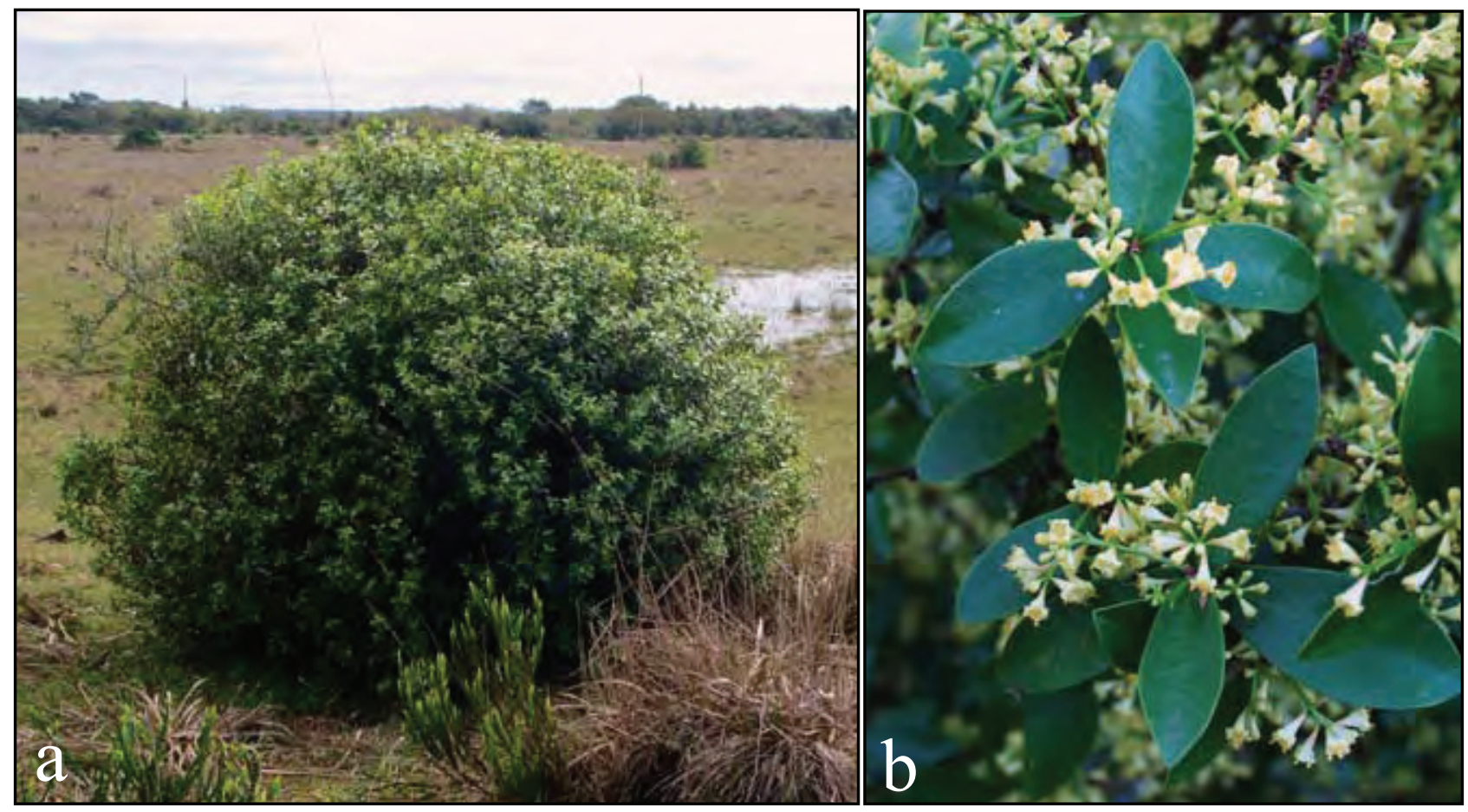

Figura 3. Daphnopsis racemosa: hábito (esquerda) e ramos com flores (direita).

Figure 3. Daphnopsis racemosa: habit (a) and stems with flowers (b). 
Eriocaulon magnificum (figura 4), da família Eriocaulaceae, é uma planta herbácea, simétrica, típica de ambiente úmido ou alagadiço. No Rio Grande do Sul é encontrada nos campos litorâneos e em beira de matas alagadiças de restinga. Conhecida como capipoatinga ou sempre-vivado-campo, apresenta folhas verde-claras, brilhantes, lisas e glabras. Os capítulos solitários, globosos a semi-globosos, de coloração branca e sem aroma, surgem no ápice de suas longas hastes. Em jardins pode ser implantada diretamente no solo, isoladamente ou formando conjuntos em locais mal drenados ou em beira de lagos, conferindo leveza na época da floração devido à cor e ao aspecto de suas inflorescências. É indicada também para o cultivo em vasos alocados a pleno sol.
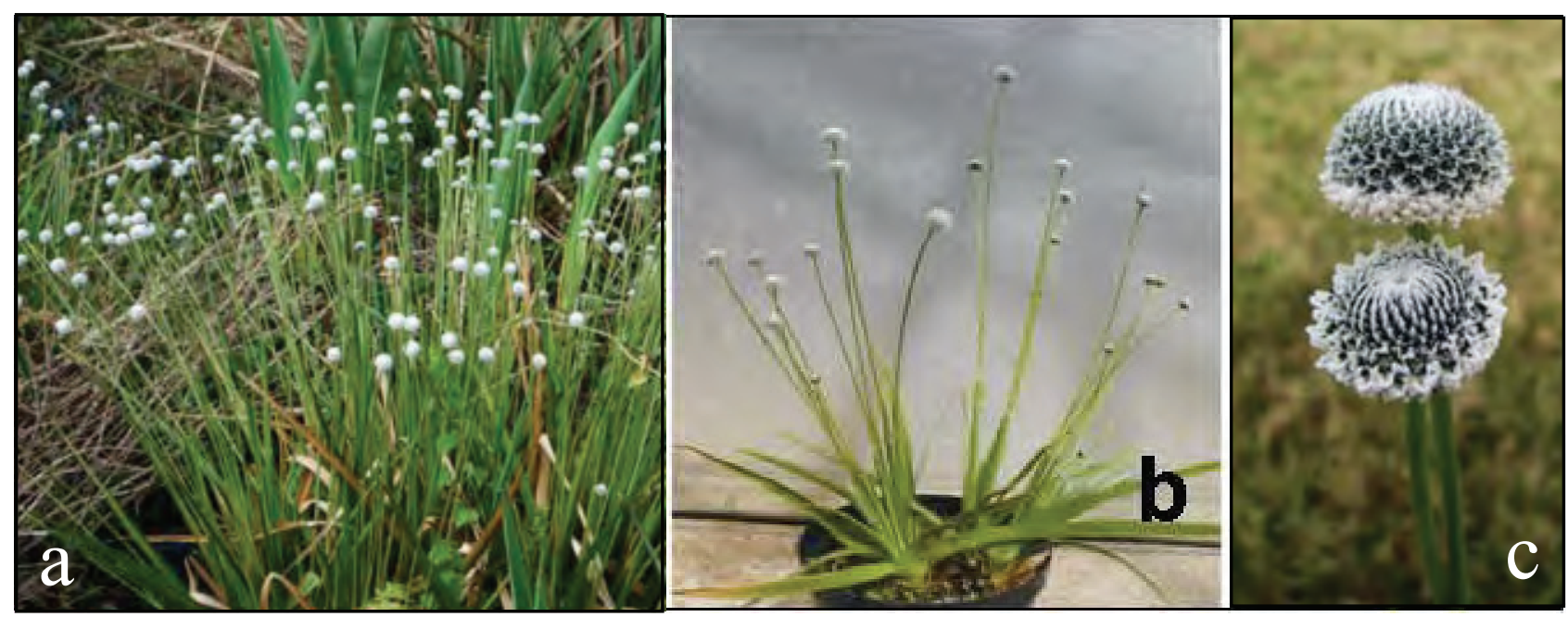

Figura 4. Eriocaulon magnificum: habitat (a), hábito (b) e inflorescência (c).

Figure 4. Eriocaulon magnificum: habitat (a), habit (b) and inflorescence (c).

Maytenus muelleri (figura 5) - mais comumente referida na literatura pelo sinônimo Maytenus ilicifolia, da família Celastraceae - é conhecida como espinheira-santa, sendo muito utilizada na medicina popular. Pode ser encontrada em campo aberto, e também no interior e borda de matas, o que mostra sua adaptação a diferentes condições de luminosidade. É uma espécie de porte arbustivo que pode atingir até $3 \mathrm{~m}$ de altura, de forma verticalizada e assimétrica. Suas folhas são simples, brilhantes, lisas, glabras e coriáceas, com coloração verde-escuro e com margem provida de espinhos. As flores são pequenas e amareladas, sem aroma e expressão ornamental. Os frutos, do tipo cápsula, atrativos para a avifauna, podem ser de arredondados a alongados, com coloração alaranjada a vermelho intenso. É indicada para o plantio em vasos; em jardins, pode ser cultivada isoladamente ou formando maciços.

Schinus lentiscifolius (figura 6) pertence à família Anacardiaceae, e é conhecida popularmente como aroeira-cinzenta, aroeira-do-rio-grande ou carobá. É encontrada nos campos, tanto isoladamente como em grupos, e principalmente em solos rasos (FLEIG, 1989), sendo usada para lenha, como melífera e também para fim medicinal (KLAMT \& SCHNEIDER, 2004). A aroeira-cinzenta é uma árvore com forma horizontalizada e assimétrica que pode atingir até $3 \mathrm{~m}$ de altura. Seus ramos, de coloração acinzentada, e suas folhas - opacas, lisas e glabras, com folíolos oblongos acinzentados - ao serem manuseados, desprendem aroma agradável. Por suas cores, proporciona um contraste com as demais plantas de um jardim, podendo ser usada como fundo de uma composição, para a formação de conjuntos ou cercas-vivas, ou ainda, isoladamente.

Scoparia ericacea (figura 7) é uma espécie da família Plantaginaceae, popularmente conhecida como vassourinha. É um arbusto com forma verticalizada e assimétrica, que se adapta melhor em solos arenosos. Tem folhas simples, filiformes, brilhantes, lisas, glabras, com coloração verde-clara e aspecto delicado. Suas flores, muito aromáticas, são simples e apresentam quatro pétalas de cor azul intenso, que a fazem se destacar dentre a vegetação. A coloração, o aspecto suave e delicado, e o aroma de suas flores são características favoráveis para o uso no paisagismo, especialmente pela escassa oferta de flores com essa coloração. É indicada para bordaduras de canteiros ou para compor maciços em jardins. Além disso, devido ao seu pequeno porte, pode ser cultivada em vasos ou floreiras instalados a pleno sol.

Senecio bonariensis (figura 8) é uma espécie da família Asteraceae, conhecida como margarida-do-banhado. É uma planta herbácea, simétrica, perene e ereta, que apresenta propriedades medicinais e é comum em terrenos alagados e margens de lagoas e rios. Possui folhas grandes e sagitadas, brilhantes, lisas, glabras e de coloração verdeclaro. As hastes florais, medindo entre 1 e $2 \mathrm{~m}$ de altura, apresentam numerosos capítulos (margaridas) aromáticos, com flores radiais liguladas brancas, e centrais amarelas. A espécie é própria para jardins com fontes de água ou localizados em terrenos alagadiços. 


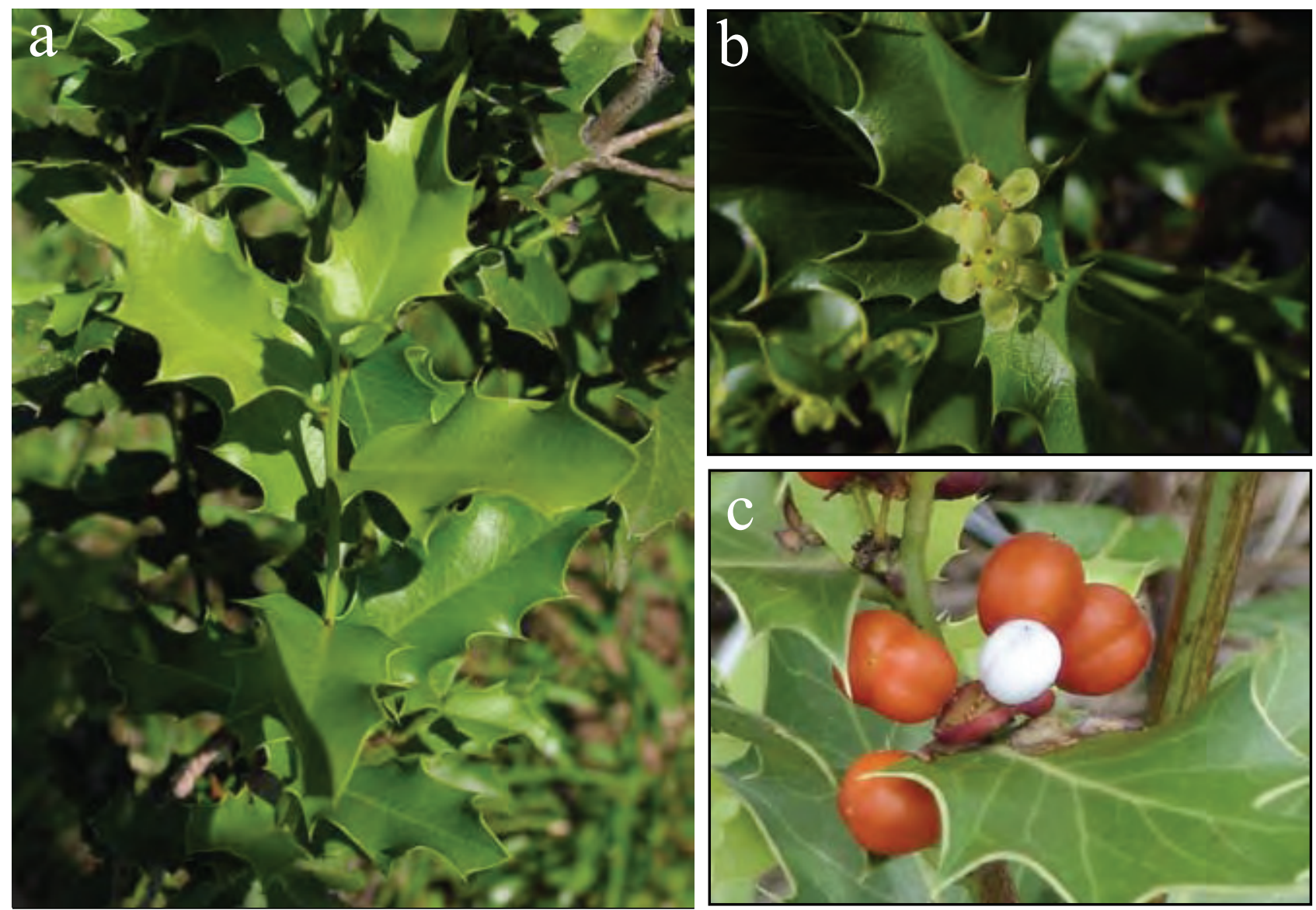

Figura 5. Maytenus muelleri: ramos com folhas (a), flores (b) e frutos (c).

Figure 5. Maytenus muelleri: stems with foliage (a), flowers (b) and fruits (c).
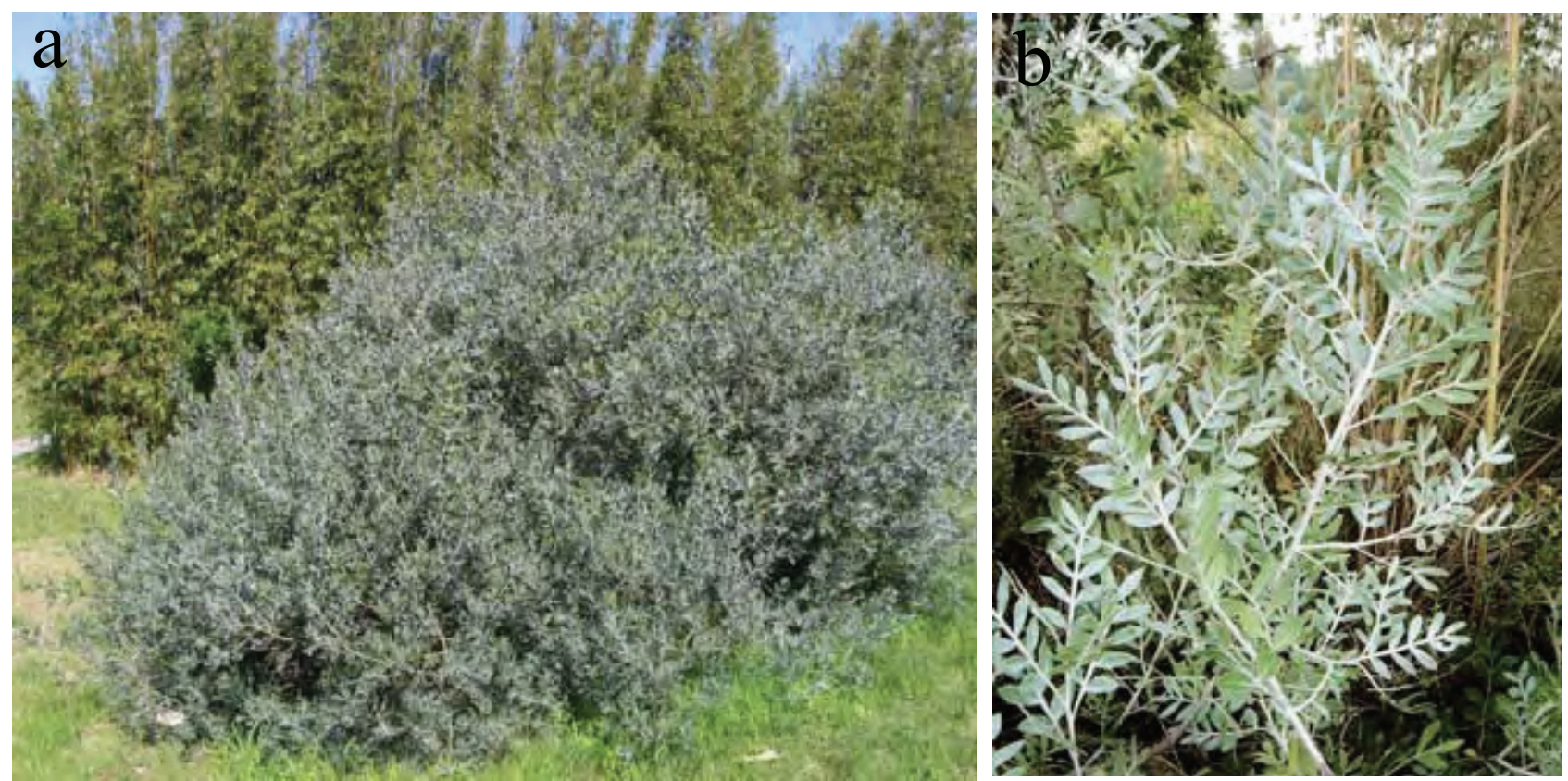

Figura 6. Schinus lentiscifolius: hábito (a) e ramo (b).

Figure 6. Schinus lentiscifolius: habit (a) and stem (b). 

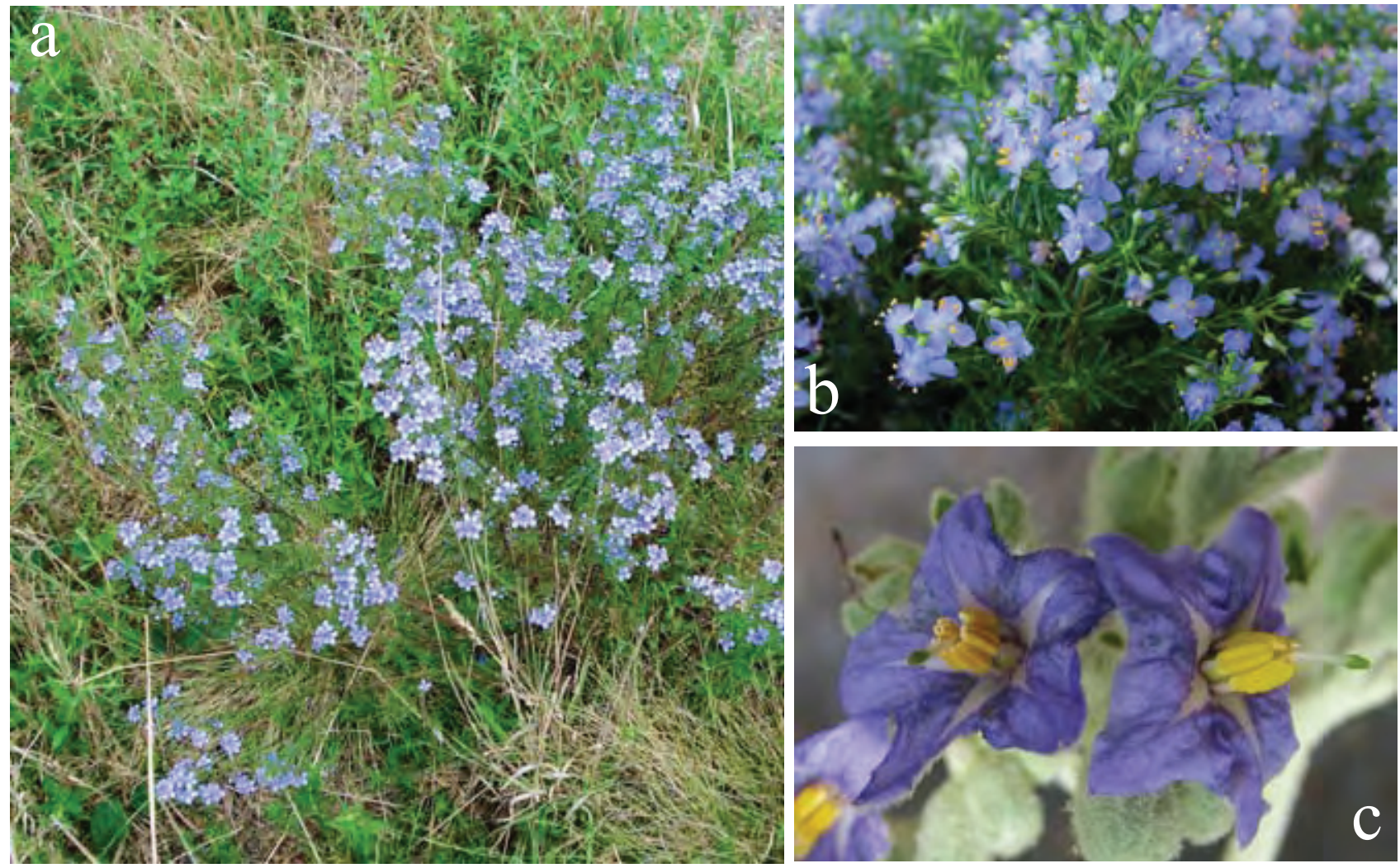

Figura 7. Scoparia ericacea: hábito (a), habitat (b) e flores (c).

Figure 7. Scoparia ericacea: habit (a), habitat (b) and flowers (c).
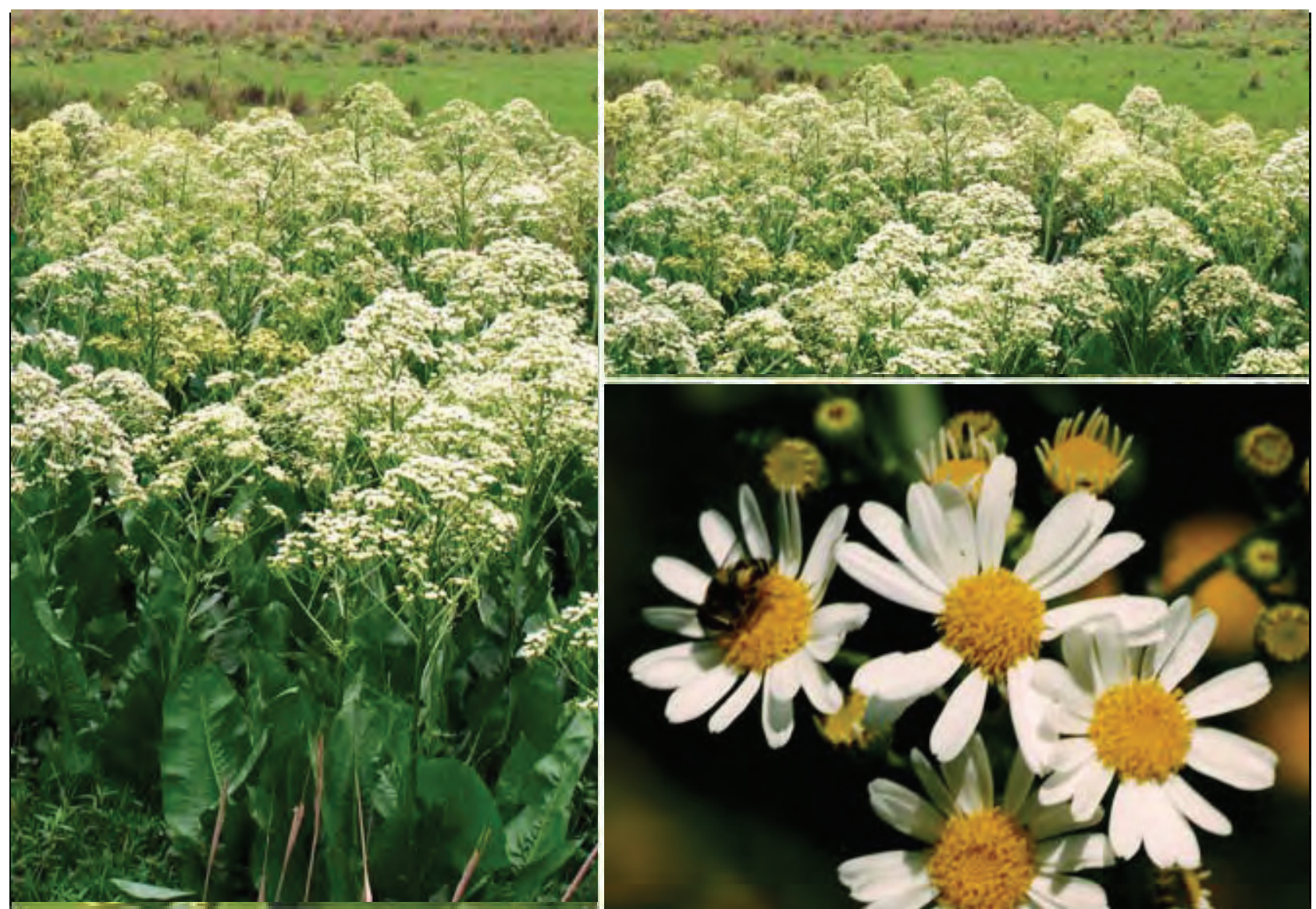

Figura 8. Senecio bonariensis: hábito (a), habitat (b) e capítulos (c).

Figure 8. Senecio bonariensis: habit (a), habitat (b) e inflorescence (c). 
Solanum granulosoleprosum (figura 9), da família Solanaceae, é conhecida como fumo-bravo ou fumeiro; espécie característica de solos argilosos e pioneira em bordas de mato e matas ciliares. É uma árvore de pequeno porte, com copa horizontalizada e assimétrica. Possui folhas verdeacinzentadas, pilosas, opacas e lisas. As inflorescências corimbiformes surgem durante o ano todo, mas sem aroma, com corola violácea e anteras amarelo-vivo. Os frutos são globosos e passam do verde até o amarelo durante a maturação. Pela arquitetura diferenciada, a coloração das folhas, flores e frutos, e pelo longo período de floração e frutificação, mostra plenas condições para uso no paisagismo. Em jardins pode ser utilizada como planta de destaque ou mesmo para compor pequenos agrupamentos. Sua forma permite o uso em terrenos irregulares, atribuindo idéia de amplitude e de horizontalidade aos espaços.
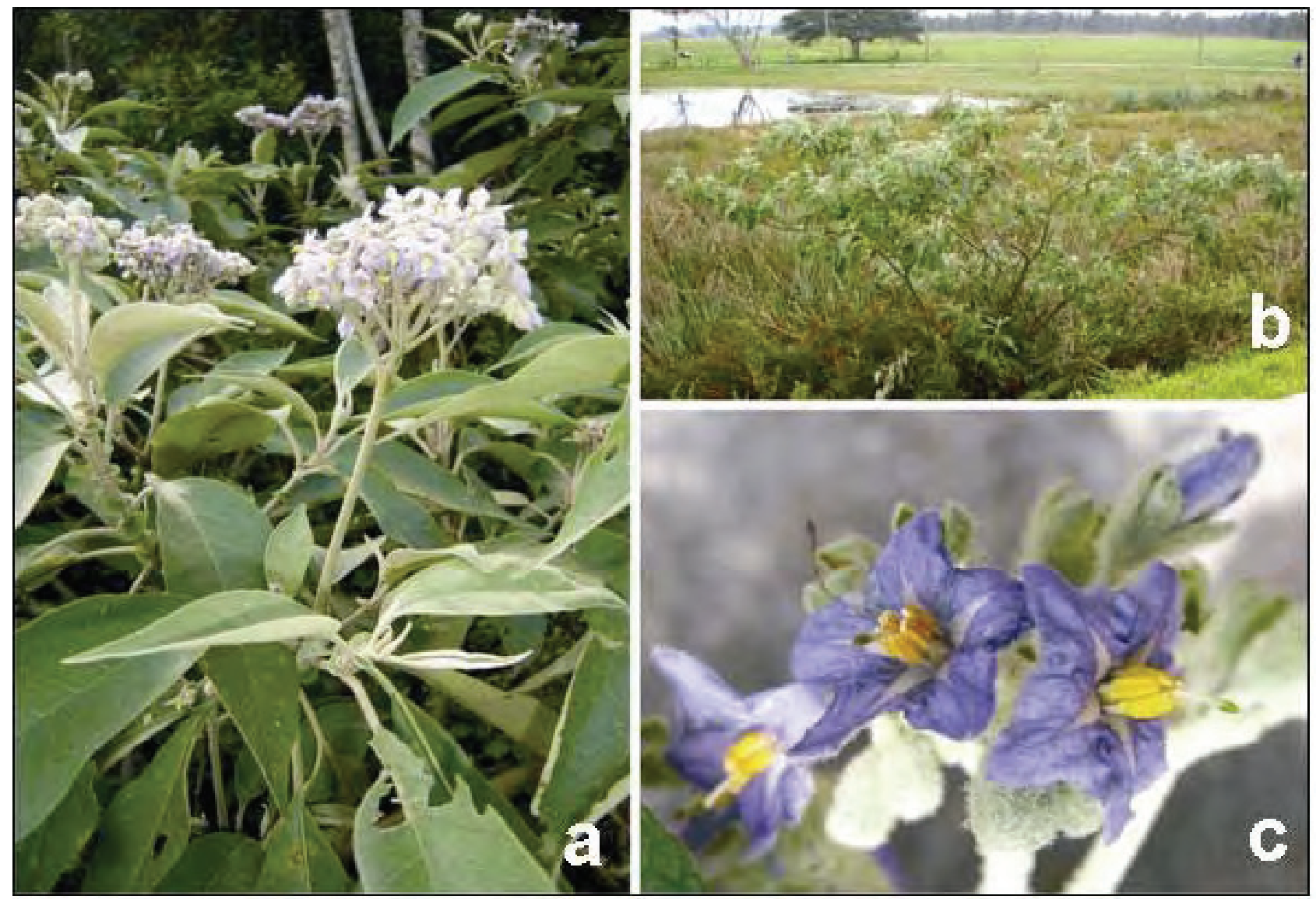

Figura 9. Solanum granulosoleprosum: ramo e inflorescência (a), habitat e hábito (b) e flores (c).

Figure 9. Solanum granulosoleprosum: stem and inflorescence (a), habitat and habit (b) and flowers (c).

A descrição das características ornamentais das espécies descritas anteriormente está sumarizada na tabela 3. 


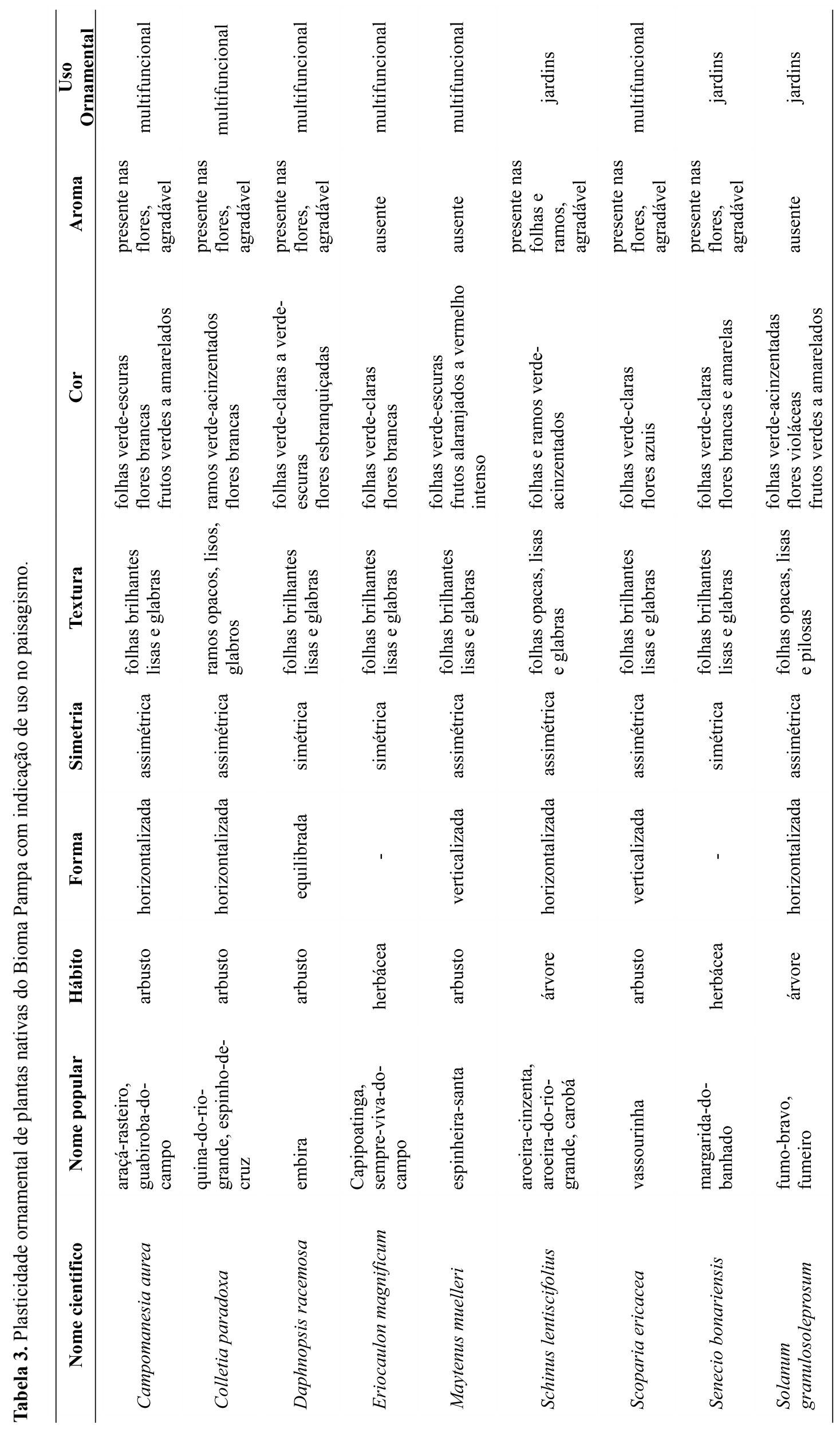




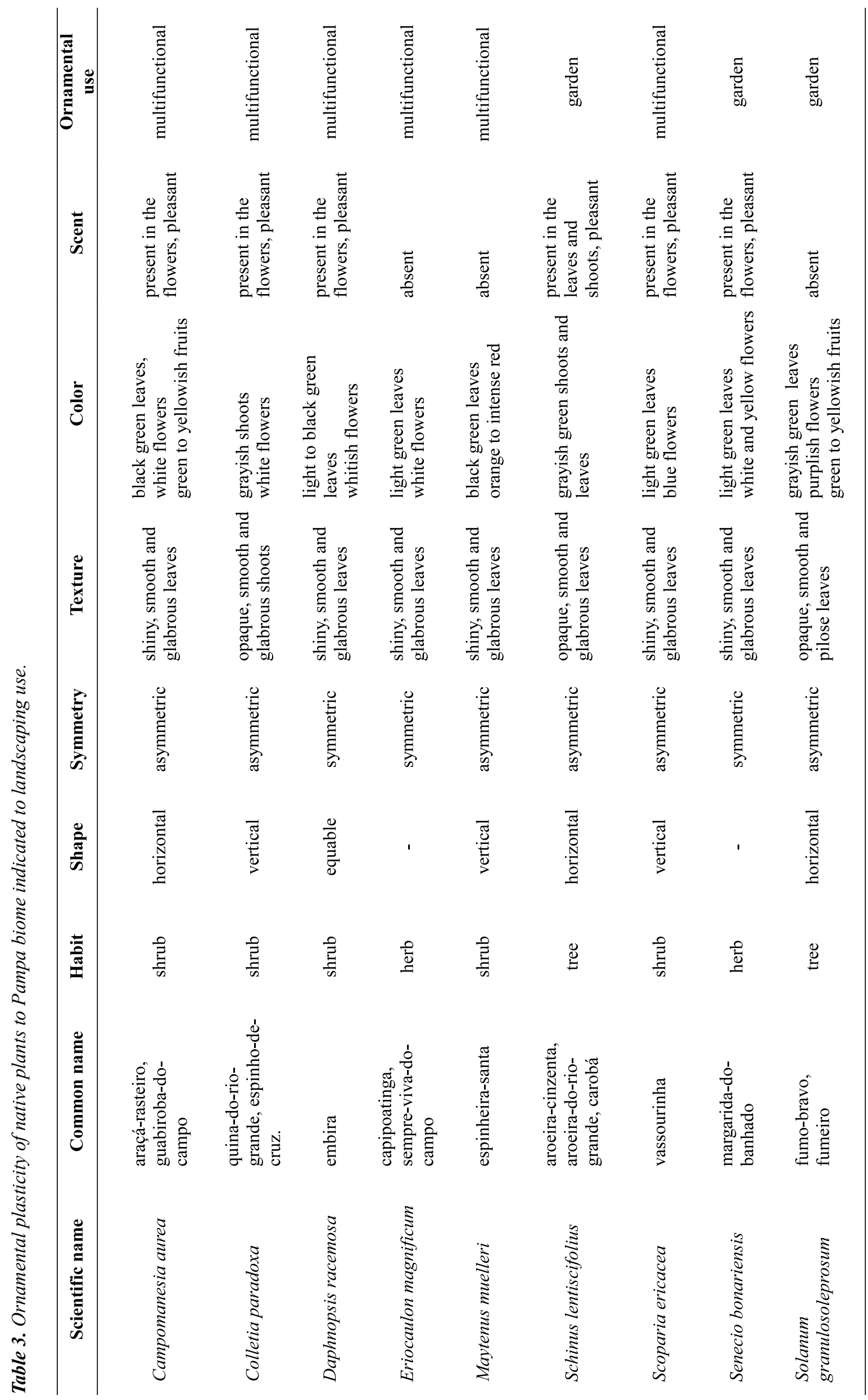




\section{CONCLUSÕES}

Campomanesia aurea, Colletia paradoxa, Daphnopsis racemosa, Eriocaulon magnificum, Maytenus muelleri, Schinus lentiscifolius, Scoparia ericacea, Senecio bonariensis e Solanum granulosoleprosum, nativas do Bioma Pampa, encontradas na região sul do Rio Grande do Sul, têm elementos estéticos apropriados para uso no paisagismo.

\section{AGRADECIMENTOS}

Ao apoio financeiro do CNPq e da FAPERGS.

\section{REFERÊNCIAS}

BACKES. P. Lutzenberger e a Paisagem. Porto Alegre: Paisagem do Sul, 2005. 208p.

BIODIVERSIDADE-RS. Espécies em risco de extinção. Disponível em: $<$ http://www.biodiversidade.rs.gov.br/portal $/$ index.php?acao $=$ especies_ameacadas $\&$ id $=528 \&$ tipo $=2$ >. Acesso em 27/07/2008.

BORTOLUZZI, L.R.; SOUZA, M.V. O dia do Bioma Pampa. Biodiversidade Pampeana. Uruguaiana, v.5, n.2, p.2, 2007.

COLLARES, J.E.R. Mapa dos Biomas do Brasil. In: Os avanços da botânica no início do século XXI: morfologia, fisiologia, taxonomia, ecologia e genética. In: CONGRESSO NACIONAL DE BOTÂNICA, 57, Gramado, 2006. Anais... Porto Alegre: Sociedade Botânica do Brasil, 2006. p.306-309.

FLEIG, M. Anacardiáceas. Itajaí: Herbário Barbosa Rodrigues, 1989. 49p. (Flora Ilustrada Catarinense).

FISCHER, S. Z.; STUMPF, E. R.T.; HEIDEN, G.; BARBIERI, R. L.; WASUM, R. A. Plantas da flora brasileira no mercado internacional de floricultura. Revista Brasileira de Biociências, Porto Alegre, v.5, n.1, p.510-512, 2007.

HEIDEN, G.; BARBIERI, R. L.; STUMPF, E. T. Considerações sobre o uso de plantas ornamentais nativas. Revis- ta Brasileira de Horticultura Ornamental, Campinas, v.12, p.1-7, 2006.

HEIDEN, G.; BARBIERI, R. L.; STUMPF, E. R. T.; GROLLI, P. R. Uso de plantas arbóreas e arbustivas nativas do Rio Grande do Sul como alternativa a ornamentais exóticas. Revista Brasileira de Agroecologia, Porto Alegre, v.2, p.851-853, 2007.

IBGE. Mapa de Biomas e de vegetação. Disponível em: $\quad<$ http://www.ibge.gov.br/home/presidencia/noticias/noticia_visualiza.php?id_noticia $=169>$. Acesso em 10/06/2008.

KLAMT, E.; SCHNEIDER, P. Características e vocação de uso agrícola do agroecossistema dos solos de profundidade média a rasos da Serra do Sudeste/RS. Porto Alegre: Secretaria Extraordinária de Reforma Agrária e Cooperativismo, 2004, 79p.

NABINGER, C. Potencialidades do Bioma Pampa. In: NAT BRASIL. O Pampa em disputa: a biodiversidade ameaçada pela expansão das monoculturas de árvores. Porto Alegre: Núcleo Amigos da Terra Brasil, 2007. 64p.

O'BRIEN, B.C. Xeriscaping: Sources of new native ornamental plants. In: JANICK, J. Progress in new crops. Arlington: ASHS, 1996. p.536-539.

TOMBOLATO, A.F.C. Potencial ornamental das espécies nativas. Revista Brasileira de Horticultura Ornamental, Campinas, v 14, n 1, p. 27-28, 2008.

VALLS, J. F. M. Manejo de Recursos Genéticos Nativos: o exemplo de Arachis. In: MARIATH, J.E.A.; SANTOS, R.P. (org.). Os avanços da botânica no início do século XXI: morfologia, fisiologia, taxonomia, ecologia e genética. Porto Alegre: Sociedade Botânica do Brasil, 2006, p. 157-161.

WEISS, D. Introduction of new cut flowers: domestication of new species and introduction of new traits not found in commercial varieties. p.129-137. In: VAINSTEIN, A. (ed.). Breeding for Ornamentals, Dordrecht: Springer, 2002. 450p. 
